\title{
Parameters affecting gap detection in the rat
}

\author{
DONALD S. LEITNER \\ Saint Joseph's University, Philadelphia, Pennsylvania \\ GEOFFREY R. HAMMOND \\ University of Western Australia, Nedlands, Western Australia, Australia \\ and
}
CHARLES P. SPRINGER, KEVIN M. INGHAM, ANN M. MEKILO, PRESTON R. BODISON, MARIA T. ARANDA, and MARLA A. SHAWARYN
Saint Joseph's University, Philadelphia, Pennsylvania

\begin{abstract}
The present research used a startle amplitude reduction paradigm to investigate the ability of the rat's auditory system to track rapidly changing acoustic transients. Specifically examined was the ability of brief gaps in otherwise continuous noise to reduce the amplitude of a subsequently elicited acoustic startle reflex. The duration of the gap, time between gap offset and startle elicitation (the interstimulus interval or ISI), and rise-fall characteristics of the gap were systematically varied. Consistent with previous research, gaps reliably reduced startle amplitude. Gaps 2 msec long were reliably detected, and a 50-msec ISI resulted in the greatest amplitude reduction. Gaps presented at short ISIs produced amplitude reduction that followed a different time course than did gaps presented at longer ISIs. These results may reflect differences in the length of time available for the processing of the stimulus and may involve two different processes.
\end{abstract}

An important aspect of the functioning of the auditory system is the ability to accurately track rapidly changing acoustic transients. Auditory temporal acuity is important in the comprehension of human speech, in which temporal patterns as well as frequency spectra must be analyzed (Davis \& McCroskey, 1980; Haggard, 1985; Lauter \& Hirsh, 1985).

Auditory temporal acuity involves in part the ability to discriminate and track gaps, which are brief silent periods in otherwise continuous sound. If the auditory system continues to respond as if a recently terminated stimulus is still present, the transition to a new stimulus will be blurred and its detectability will be compromised (see, e.g., Plomp, 1964). In theory, this failure to resolve the temporal detail of acoustic information will occur to the extent that the neural activity engendered by an auditory stimulus outlasts the actual physical event (see, e.g., Penner, 1975; Williams, Elfner, \& Howse, 1979). For a gap to be detectable, according to this model, the neural activity produced by an ongoing signal must decay at signal offset to a level such that the difference between it and the increase in neural activity accompanying the return of the signal would be detectable. The smallest detectable gap would thus have a duration just long enough for this to occur.

In humans, the ability to detect gaps is at least as important as is the ability to process frequency and inten-

Reprint requests and other correspondence conceming this manuscript should be addressed to Donald S. Leitner, Department of Psychology, Saint Joseph`s University, 5600 City Avenue, Philadelphia, PA 191311395 (e-mail: dleitner@sjuphil.sju.edu). sity information in the comprehension of speech. Research has shown that the ability to detect gaps is related to performance on speech perception tests in adults (Corso, Corso, \& Corso, 1981; Trinder, 1979), that hearingimpaired persons have elevated gap detection thresholds (see, e.g., Buus \& Florentine, 1985), and that deficits in gap detection correlate with language and learning disabilities in children (McCroskey \& Kidder, 1980).

By using a number of techniques and species of animals, researchers have attempted to characterize the limits of auditory temporal resolution and the factors that affect it. Experiments have involved humans (see, e.g., Perrott \& Williams, 1971; Plomp, 1964; Williams et al., 1979), the house finch (Dooling, Zoloth, \& Baylis, 1978), and the chinchilla (Giraudi, Salvi, Henderson, \& Hamernik, 1980) as subjects. Typically the parameters that have been manipulated include the duration of the gap, the frequency characteristics, intensity, and duration of the sound in which the gap is embedded, and the temporal location of the gap within the acoustic background (see, e.g., Fitzgibbons, 1984; Forrest \& Green, 1987). Despite the diversity of techniques and species, the minimum detectable gap has consistently been demonstrated to be in the range of 2-6 msec, defining the limit of the auditory system's ability to track rapidly changing acoustic stimuli.

A gap is most readily detected when it is embedded in a high-frequency, subjectively intense acoustic signal of at least a few hundred milliseconds in duration. Deviations from these ideal conditions result in a minimum detectable gap that is longer in duration, and models of auditory processing that can account for these data have been proposed. Specifically, the ability to detect brief gaps is 
viewed as primarily the result of two independent factors: one of these is the listener's sensitivity to the spectra of the signal, especially its high-frequency components, and the other is the sensitivity of the listener's auditory system to brief changes in the signal's intensity (for a review, see Green, 1985).

The assessment techniques used in the above research are similar because they rely on the cooperation of the subject being tested, either through the following of instructions and verbal reports with human subjects or through reliance on a motivated, operant baseline performance maintained by appetitive or aversive schedules as a response measure with other species. Problems with these techniques arise when the subject cannot cooperate for one reason or another. In humans, infants and those who are developmentally handicapped are difficult to assess for hearing deficits because of their limited ability to cooperate, yet it is precisely these individuals who would most benefit from early detection and correction of hearing abnormalities (see, e.g., Benham-Dunster \& Dunster, 1985). In other species, independent variables that affect motivational states or motor coordination, such as drug administration or exposure to a stressor, can confound the assessment of sensory changes measured by operant performances.

A technique based on the modification of reflexes by innocuous sensory events that briefly precede the reflexeliciting stimuli has shown much promise as an objective tool in assessing changes in the temporal acuity of the auditory system. Many reflexes, such as the whole-body startle reflex of the rat and the reflexive human eye-blink, can be reduced in amplitude if the reflex-eliciting stimulus is preceded at an appropriate temporal interval by virtually any detectable change (prestimulus) in the sensory environment (for reviews, see Hoffman \& Ison, 1980; Ison \& Hoffman, 1983). The magnitude of the reduction in reflex amplitude is related to the detectability of the stimulus. By comparing the amplitude of the reflex on trials in which the prestimulus precedes the reflex-eliciting stimulus with the amplitude of the reflex on trials in which it is elicited without the prestimulus, the detectability of the prestimulus can be monitored objectively (see, e.g., Marsh, Hoffman, Stitt, \& Schwartz, 1975; Reiter \& Ison, 1977). Subjects do not have to be trained, and their cooperation is not needed.

Techniques involving reflex modification that utilized brief pulses of pure tones or white noise as prestimuli have been successfully used in a variety of situations to assess changes in auditory functioning (for a review, see Crofton, 1992). To date, however, there have been relatively few investigations either of gaps as reflex-modifying events or of the parameters that affect amplitude reduction by gap prestimuli. Ison (1982) used gaps in white noise in a reflex-reduction paradigm to assess temporal resolution in rats and found that the threshold for detection was about $3.5 \mathrm{msec}$. This compares favorably with measures obtained by other methods and from other species, and was the first documentation of the limit of auditory temporal acuity in the rat. The variables manipulated were the duration of the gap and the temporal relationship between the gap and the reflex-eliciting stimulus. Ison and Pinckney (1983) replicated this experiment using human subjects and found that the results with a reflex-reduction paradigm agreed closely with gap-detection thresholds obtained using the method of limits.

The data collected by Ison (1982) were paradoxicalhe found no pronounced increases in the ability of a gap to reduce startle amplitude as gap duration increased beyond $7 \mathrm{msec}$ as long as the temporal interval between gap onset and the startle-eliciting stimulus onset (the stimulus onset asynchrony, or SOA) was $190 \mathrm{msec}$. Gaps continued to increase in their ability to reduce startle amplitude, however, as their duration grew toward $40 \mathrm{msec}$ if the SOA was reduced to $40 \mathrm{msec}$. This was the first time in over 20 years of research focusing on reflex modification that such a second temporal process had been reported.

More recently, Ison, O'Connor, Bowen, and Bocirnea (1991) essentially replicated these findings in rats; gaps presented at short SOAs continued to increase in their ability to reduce startle amplitude as their duration increased from 2 to $30 \mathrm{msec}$. Gaps presented at long SOAs produced a maximum degree of reflex reduction at durations of $4 \mathrm{msec}$, beyond which increases in duration did not cause further reductions of startle amplitude. They also found that functional decortication by topical application of a potassium chloride solution eliminated the amplitude reduction produced by gaps presented at long, but not short, SOAs. They concluded that the use of long SOAs allowed time for a greater degree of sensory processing of the gap, thus short gaps had a greater sensory impact. The use of short SOAs did not permit this, and so a more salient (i.e., longer) gap was needed to produce a comparable degree of startle amplitude reduction. The sensory processing that made short gaps effective at longer SOAs reflected cortical influence, since functional decortication eliminated this phenomenon.

The present series of experiments are an extension of the research conducted by Ison (1982) and Ison et al. (1991). In the present research, the temporal interval between gap offset and the startle-eliciting stimulus (SES) onset, the duration of the gap itself, and the rise-fall time of the gap were each varied systematically over a large range of values. In contrast with the research conducted by Ison (1982), gap offset-not gap onset-was used as the reference point for determining the temporal distance between the gap and the onset of the SES because, for gaps of a specific duration, this kept the time between the gap and the onset of the SES constant during the critical period immediately before the elicitation of startle.

This change of reference point was intended to control for an inevitable confound built into this sort of an experiment, noted by Ison (1982). If the onset of the gap is used as the reference point for determining the temporal distance between the gap and the onset of the SES, the duration of the gap will be confounded with the duration of the acoustic background between the gap offset 
and the onset of the SES - the longer the gap, the shorter the background duration will be. If, on the other hand, the gap offset is used as the reference point, the duration of the gap will be confounded with the duration of the acoustic background that precedes the onset of the gapthe longer the gap, the shorter the duration of the background will be.

The use of gap offset as a reference point produced a systematic variation in the duration of the acoustic signal that preceded the gap as the gap duration varied, as discussed above. To control for this, the duration of the acoustic signal that preceded the gap (the intertrial interval) was varied at random from trial to trial among several values, the shortest of which was $16 \mathrm{sec}$. Since the duration of the gaps varied by tens of milliseconds at most, it is doubtful that the small contribution that they made to variations in the duration of the acoustic signal that preceded the gaps would be detectable, given that the random variation of the intertrial interval was orders of magnitude greater.

Also used in the present research were two sorts of control trials. One type was used by Ison (1982) and Ison et al. (1991) and consisted of a trial in which the SES was presented after a period of unbroken background noise (a "no gap" condition). The other type consisted of the rise-fall time associated with the gap being presented before the SES, without the gap itself (a zero-duration gap condition). On these trials, the background noise declined to silence and then immediately began its return to its original amplitude. These trials were included to assess the detectability of any high-frequency transients that might be generated by the rapid switching of the background noise needed to produce the gap. Such transients, if present, would presumably make the gaps easier to detect.

\section{EXPERIMENT 1}

\section{Method}

Subjects. The subjects were 12 male albino Sprague-Dawley rats, all approximately 90 days old at the beginning of testing. They were individually housed and allowed ad lib food and water except during testing. They were maintained on a 10:14-h reversed dark:light cycle and tested within a few hours of the midpoint of the "night" portion of the cycle.

Apparatus. An Apple Ile microcomputer was used to control all programming, logic, timing, and response measurement functions, supplemented with Coulbourn Instruments solid-state modules where necessary. A printer linked with the computer supplied hard copy of all data.

The dependent variable in this experiment was the amplitude of the rat's whole-body acoustic startle reflex. To measure this, the subjects were placed individually in one of two small plastic tubs $(20 \times 10 \times 10 \mathrm{~cm})$ fitted with lids that snapped securely onto the tops. A rectangular section of each of the lids $(15 \times 7.5 \mathrm{~cm})$ had been cut out and replaced with an acoustically transparent aluminum mesh to allow good penetration of the stimuli into the tub. During testing, each of these containers was placed on one of two Coulbourn Instruments movement transducer platforms (Model E45-12). The output voltages from the platforms' strain gauge bridges (Coulbourn Instruments Model S72-25) were sent through low-pass filters with cutoff frequencies of $30 \mathrm{~Hz}$, rectified, integrated, and passed to a
Computer Continuum 8-bit analog/digital-digital/analog converter board. The Apple IIe microcomputer sampled the incoming voltages at a frequency of $1000 \mathrm{~Hz}$ for $150 \mathrm{msec}$, beginning with the onset of the SES; the peak values during this interval served as the rats' response amplitude on that trial.

The two platforms were located in a sound-attenuated chamber, heavily treated on the inside with an anechoic material. Located $22.5 \mathrm{~cm}$ above each platform were three Radio Shack ultrahigh frequency tweeters (Model 40-1377), with output spectra that reflected fairly flat frequency response from 5 to $40 \mathrm{kHz}$. Two of these transducers, wired in parallel, were used to deliver the SES, and the third was used for the background white noise in which the gap was embedded.

The background white noise was set at $60 \mathrm{~dB}$ SPL(A). (An A-weighted scale was used for all noise measurements so that the measured intensities of the stimuli would correspond more closely to the frequency sensitivity of the rat.) The rise-fall time of the gap was controlled by increasing or decreasing the gain of a voltagecontrolied amplifier (Coulbourn Instruments Model S77-05); the controlling voltage was supplied by the Computer Continuum 8-bit analog/digital-digital/analog converter board, which was programmed to increase or decrease its output voltage according to a cosine function. The SES was a 120-dB-SPL(A) burst of white noise, with a $100-\mu \mathrm{sec}$ rise-fall time and a duration of $50 \mathrm{msec}$. Both the background noise and the SES were produced by Coulbourn Instruments white noise generators (Model S81-02) modified so that their output spectra were flat to approximately $100000 \mathrm{~Hz}$. The stimuli were amplified with a Crown solid-state stereo amplifier (Model DC300).

Procedure. The basic paradigm consisted of the repeated presentation of the SES, with an intertrial interval that varied among $16,18,20,22$, and $24 \mathrm{sec}$ in a random fashion. Present throughout testing was the background white noise in which the gap, if present on a particular trial, was embedded. A trial thus consisted of an average of $20 \mathrm{sec}$ of white noise and ended with the presentation of the gap and the SES, and the assessment of startle amplitude. The next trial began immediately, with the white noise continuing for approximately $20 \mathrm{sec}$ before another gap and SES was presented, and so on.

Variations in the duration of the gap and the temporal relationship between the gap and the SES were the independent variables investigated in this experiment. Gap duration was varied among $1,2,3,4,5,6,8$, and $10 \mathrm{msec}$. Also included were trials in which the SES was presented alone (no-gap trials), and trials in which a zero-duration gap was presented, as mentioned above. The zeroduration gap consisted of only the rise-fall characteristics of the gaps. The rise-fall time used for all gaps and for the zero-duration gap trials was fixed at $1 \mathrm{msec}$ to minimize high-frequency transients that are commonly generated by the rapid switching of an acoustic stimulus; these trials were included to determine whether or not the rise-fall characteristics of the gaps were detectable. These 10 types of trials were presented 30 times each in a block randomized sequence, making a total of 300 trials for a given test session.

Each rat was exposed to six test sessions, spaced at least $48 \mathrm{~h}$ apart. Varied between test sessions for each rat was the time between gap offset and the onset of the SES (the interstimulus interval, or ISI). The ISIs used were $25,50,75,100,150$, and $200 \mathrm{msec}$. These were presented to each rat in a sequence determined by a Latin square matrix. Thus, each subject was exposed to a total of 60 experimental conditions, representing the factorial combinations of the two independent variables.

\section{Results}

Mean startle amplitude was computed for each rat for each condition, and grand means were then computed across subjects for each condition. The grand means are 


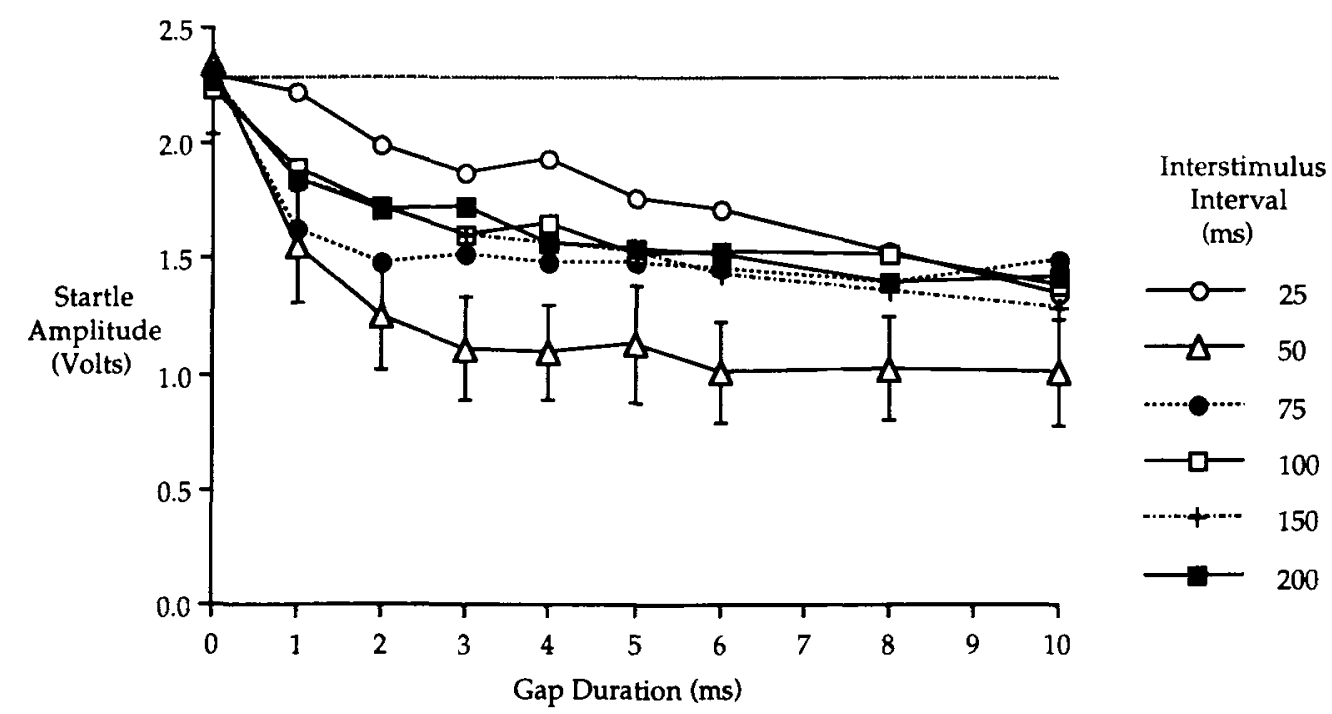

Figure 1. Mean startle amplitude as a function of gap duration and interstimulus interval (ISI). The line at the top running parallel to the horizontal axis represents the grand mean of the "no gap" condition. (Vertical error bars for 50 -msec ISI represent \pm 1 SEM.)

depicted in Figure 1. For the sake of clarity, the standard error of the mean (SEM) is shown only for the gaps presented at a 50 -msec ISI; the value of the $S E M$ was about the same for all experimental conditions. The line parallel to the horizontal axis represents the mean, computed across the ISIs used, of the grand means for the no-gap condition.

It can be seen that the zero-gap condition was not different from the no-gap condition, indicating that the rise-fall time used was by itself not detectable. It also appears that the longer the gap duration, the greater was the reduction in reflex amplitude. Surprisingly, even the shortest gap used, only $1 \mathrm{msec}$ in duration, appears to have been able to reduce reflex amplitude.

It also can be seen that an ISI of $50 \mathrm{msec}$ produced the most pronounced reflex amplitude reduction, whereas an ISI of $25 \mathrm{msec}$ produced the least. The other ISI values used were clustered together between these two. With the exception of the $25-\mathrm{msec}$ ISI, the functions depicted by the plotted data for each of the ISIs seem to be best described by two straight lines, one with a steep slope that extends from gap durations of 0 to $2 \mathrm{msec}$ and a second of lesser slope that extends from gap durations of 3 to $10 \mathrm{msec}$. The 25 -msec ISI data seem to be best described by a single straight line. The slope of this line is steeper than that of any of the other functions depicted from gap durations of 3 to $10 \mathrm{msec}$.

These trends were tested for statistical reliability using a 10 (gap duration) $\times 6$ (ISI) analysis of variance (ANOVA) with repeated measures on both factors. A main effect was found for gap duration $[F(9,649)=32.52, p<.001]$ and for ISI $[F(5,649)=11.15, p<.001]$; their interaction was not reliable $[F(45,649)=.67$, n.s. $)$.

The data were further analyzed using post hoc Tukey tests. It was found that, overall, the 50 -msec ISI condi- tion was reliably different from all others $(p<.05)$ and that the 25-msec ISI condition was reliably different from the $75-$ and $150-\mathrm{msec}$ ISI conditions $(p<.05)$. No other comparisons were reliably different.

It was further found that, overall, the 10-msec gap was reliably different from the no-gap, zero-gap, 1-msec gap, and $2-\mathrm{msec}$ gap conditions $(p<.05)$, and that the 8-msec-gap, 6-msec-gap, and 5-msec-gap conditions were reliably different from the no-gap, zero-gap, and 1-msecgap conditions $(p<.05)$. The 4-msec-gap, 3-msec-gap, 2 -msec-gap, and 1-msec-gap conditions were reliably different from the no-gap and zero-gap conditions $(p<.05)$. No other comparisons were reliably different.

\section{Discussion}

A number of conclusions can be drawn from these data. Consistent with previous research (Ison, 1982; Ison et al. 1991), a gap in otherwise continuous noise reliably reduced the amplitude of the rat's acoustic startle reflex. Also consistent with previous research (e.g., Marsh et al., 1975; Schwartz, Hoffman, Stitt, \& Marsh, 1976), an inverse relationship was found between reflex amplitude reduction and stimulus saliency-the larger the gap, the greater the degree of reflex reduction. The 50-msec ISI produced the greatest degree of reflex reduction in the present study. This is consistent with the findings of other studies that used pulses of noise or pure tones as prestimuli (see, e.g., Hoffman, Stitt, \& Leitner, 1980).

Surprisingly, gaps as brief as $1 \mathrm{msec}$ were able to reliably reduce reflex amplitude in the present study. This indicates that these brief gaps were detectable to the subjects. The 1-msec value falls below the range of reported values, obtained through other techniques, that estimate the limit of auditory temporal resolution; it is also less than the estimate of $3.5 \mathrm{msec}$ reported by Ison (1982) 
using a technique very similar to the one used in the present study. One explanation for the difference between the present findings and those of Ison may be that the results reported here are based on the assumption that since a gap of $1 \mathrm{msec}$ in duration reliably reduced reflex amplitude, it must have been detectable. Ison defined gap detection threshold as the gap duration that reduced reflex amplitude half as well as the most effective gap duration. Applying this technique to the data for an ISI of $50 \mathrm{msec}$ in the present study still results in a "threshold" estimate of $1 \mathrm{msec}$.

A more likely reason for the differences between the present findings and those of Ison (1982) may be the different rise-fall times used. The present study used a risefall time of $1 \mathrm{msec}$, whereas the rise-fall time used by Ison was much less than $1 \mathrm{msec}$. It is possible that the longer rise-fall time used in the present research, although not detectable by itself, enhanced the saliency of the gaps to the point where even the briefest duration used was detectable. This possibility is examined in Experiment 3, in which the rise-fall time is systematically varied.

Previous research has shown that prestimuli presented at ISIs shorter or longer than the optimum of approximately 50 msec produce a lesser degree of reflex reduction (Hoffman et al., 1980). In the present study, gap prestimuli produced reflex reduction that grew rapidly as the ISI moved from 25 to $50 \mathrm{msec}$, and then decreased less rapidly as the ISI moved to $75 \mathrm{msec}$. If the efficacy of very brief gaps in reducing startle amplitude is interpreted as a reflection of greater cortical processing, as suggested by Ison et al. (1991), this process would appear to be maximal at ISIs of approximately $50 \mathrm{msec}$, declining thereafter.

Ison (1982) found that an interaction existed between gap duration and ISI-gaps of long duration engendered the greatest degree of reflex reduction at short ISIs, whereas brief gaps were most effective in reducing reflex amplitude if they were presented at long ISIs. The author used gaps as long as $\mathbf{4 0} \mathrm{msec}$ to demonstrate this. No reliable interaction was found between gap duration and ISI in the present study, but the longest gap duration used was $10 \mathrm{msec}$ as opposed to $40 \mathrm{msec}$; the values used for ISIs corresponded to those used by Ison.

Despite this, the functions obtained in the present study are very similar to those found in previous research. The plots of the data for ISIs of 50,75, 100,150, and $200 \mathrm{msec}$, depicted in Figure 1, correspond closely to the shape of the functions previously reported for gaps presented at "long" (190 msec) ISIs by Ison (1982). Furthermore, the plot of the data in the present study for an ISI of 25 msec corresponds closely to the shape of the functions previously reported for gaps presented at "short" (40 msec) ISIs by Ison. As mentioned above, the plot for the 25-msec ISI can also be seen to have the steepest slope for gap durations of 3 to $10 \mathrm{msec}$, compared with the other plots. Although no reliable interaction between gap duration and ISI was found in the present study, it is possible that an interaction would have been identifiable if a greater range of values of gap duration had been used.
Experiment 2 explores this possibility, utilizing a greater range of gap durations and also a greater range of ISIs.

\section{EXPERIMENT 2}

Experiment 2 was identical in most details to Experiment 1 . It differed in that, as noted above, a greater range of values was used for the ISIs. Also, a greater range of values was used for gap duration, again including values that corresponded to those used by Ison (1982).

\section{Method}

Subjects. The subjects were 10 male albino Sprague-Dawley rats They were similar in all respects to the subjects used in Experiment 1 and were housed under identical conditions.

Apparatus. The equipment used in Experiment 2 was identical to that used in Experiment 1.

Procedure. The procedure used in Experiment 2 was almost identical to that used in Experiment 1 . The gap durations were varied among 5, 10, 15, 20, 25,30, 40, and $50 \mathrm{msec}$. No-gap trials and zero-gap trials were also included. The ISIs were varied among 20 , $30,50,100,200,300$, and 500 msec. Each subject was exposed to a total of 70 experimental conditions, representing the factorial combinations of the two independent variables.

\section{Results}

As in Experiment 1, mean startle amplitude was computed for each rat for each condition, and grand means were then computed across subjects for each condition. The grand means are depicted in Figure 2. For the sake of clarity, the $S E M$ is shown only for the gaps presented at a 500-msec ISI; as in Experiment 1, the value of the $S E M$ was about the same for all experimental conditions. The line parallel to the horizontal axis represents the mean, computed across the ISIs used, of the grand means for the no-gap condition.

The trends noted in Experiment 1 can also be seen in the data plotted in Figure 2. With the exception of the 20- and 30-msec ISIs, the functions depicted by the plotted data for each of the other ISIs seem to be best described by two straight lines, one with a steep slope that extends from gap durations of 0 to $5 \mathrm{msec}$ and a second of lesser slope that extends from gap durations of 10 to $50 \mathrm{msec}$. The 20- and 30-msec ISI data also seem to be best described by two straight lines, except that the first has a steep slope extending from gap durations of 0 to $25 \mathrm{msec}$ and the second is essentially a straight horizontal line that extends from gap durations of 25 to $50 \mathrm{msec}$.

For the shortest gap durations, the most pronounced reflex reduction was engendered by gaps presented at an ISI of $50 \mathrm{msec}$. If one ignores the zero-gap condition, the plot of these data is virtually a straight horizontal line. At this ISI, almost maximal reflex reduction was produced by gaps of $5 \mathrm{msec}$ in duration, and there is virtually no increase in the degree of reflex reduction as gap duration increases from 5 to $50 \mathrm{msec}$.

A different pattern can be seen for the two shortest ISIs of 20 and $30 \mathrm{msec}$. A 5-msec gap produced the least reflex reduction when presented at an ISI of $20 \mathrm{msec}$, but a 50 msec gap produced the most reflex reduction when pre- 


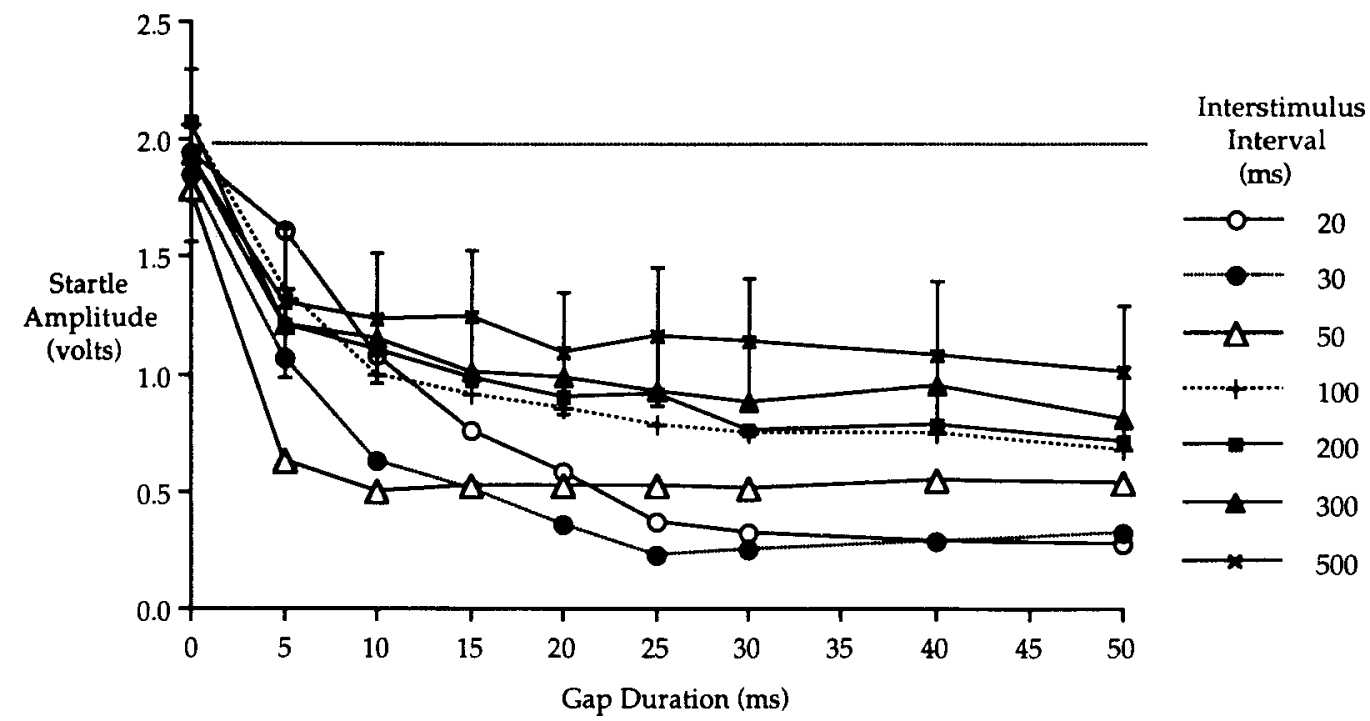

Figure 2. Mean startle amplitude as a function of gap duration and interstimulus interval (ISI). The line at the top running parallel to the horizontal axis represents the grand mean of the "no gap" condition. (Vertical error bars for 100-msec ISI represent $\pm 1 S E M$.)

sented at an ISI of $20 \mathrm{msec}$. The $30-\mathrm{msec}$ ISI shows a similar pattern at longer gap durations but is more similar to the 50-msec ISI at the shortest gap durations.

These trends were tested for statistical reliability with a 10 (gap duration) $\times 7$ (ISI) ANOVA with repeated measures on both factors. A main effect was found for gap duration $[F(9,621)=70.61, p<.001]$ and for ISI $[F(6,621)=11.15, p<.001] ;$ their interaction was not reliable $[F(54,621)=1.09$, n.s. $]$.

The data were further analyzed using post hoc Tukey tests. It was found that, overall, the 20-, 30-, and 50-msec ISI conditions were reliably different from all others $(p<$ .05 ) but not from each other. No other comparisons were reliably different.

It was further found that, overall, the 30-, 40-, and 50-msec-gap-duration conditions were reliably different from the no-gap, zero-gap, 5-msec-gap, and 10-msec-gap conditions $(p<.05)$, but not from each other. The 15-, 20 -, and 25-msec gap conditions were reliably different from the no-gap, zero-gap, and 5-msec gap conditions $(p<.05)$ but not from each other. The 5- and 10-msec gap conditions were reliably different from the no-gap and zero-gap conditions $(p<.05)$ but not from each other. All other comparisons were not reliably different.

Although the interaction between gap duration and ISI was not statistically reliable, assessing the relationship between these two variables was one of the a priori assumptions for Experiment 2. Accordingly, further analyses using post hoc Tukey tests were performed to investigate this issue. It was found that for a gap of $5 \mathrm{msec}$, an ISI of $20 \mathrm{msec}$ reliably produced the least reflex reduction, and an ISI of 50 msec produced the most $(p<.05)$. A 10-msec-gap presented at an ISI of $30 \mathrm{msec}$ was not reliably different from the same gap presented at an ISI of
$50 \mathrm{msec}$, but both produced reliably more reflex reduction than did the gap presented at a 20-msec ISI ( $p<$ .05 ). A gap of $25 \mathrm{msec}$ presented at an ISI of $30 \mathrm{msec}$ produced reliably more reflex reduction than did the same gap presented at an ISI of $50 \mathrm{msec}(p<.05)$; the gap presented at a $30-\mathrm{msec}$ ISI was not reliably different from the gap presented at ISIs of 20 or $50 \mathrm{msec}$. A gap of $40 \mathrm{msec}$ presented at an ISI of either 20 or $30 \mathrm{msec}$ produced reliably more reflex reduction than did the same gap presented at an ISI of $50 \mathrm{msec}(p<.05)$, but they were not reliably different from each other.

The trends shown in the plots for each ISI were also analyzed using post hoc Tukey tests. It was found that differences among the points making up the plot for the 20-msec ISI were no longer reliable with gap durations of $25 \mathrm{msec}$ and longer; as mentioned above, the function leveled off at this point. For the $30-\mathrm{msec}$ ISI plot, this was true at gap durations of $15 \mathrm{msec}$ and longer. For the 50-msec ISI, differences were no longer reliable with gap durations of 5-msec and longer; as mentioned above, the entire function is essentially flat save for the no-gap and zero-gap conditions. Differences among points making up the 100-msec ISI plot ceased to be reliably different at gap durations of $20 \mathrm{msec}$ and beyond; for the 200-, 300-, and 500 -msec ISI plots, the functions leveled off at $15 \mathrm{msec}$.

\section{Discussion}

The results of Experiment 2 extend the findings of Experiment 1. In Experiment 1, the function for gaps presented at an ISI of $50 \mathrm{msec}$ was virtually flat at durations of $3 \mathrm{msec}$ and beyond. In Experiment 2, this trend was continued for gaps of longer duration. Apparently increases in gap duration are not accompanied by further increases in reflex reduction when the ISI is $\mathbf{5 0 ~} \mathrm{msec}$. For 
this ISI, then, reflex reduction seems to be maximal when gap duration is a very brief $3 \mathrm{msec}$. This stands in contrast to the findings of Ison (1982), who found no pronounced increases in the ability of a gap to reduce startle amplitude as gap duration increased beyond $7 \mathrm{msec}$, when presented at an ISI of $190 \mathrm{msec}$. More recently, Ison et al. (1991) found that increases in gap duration beyond $4 \mathrm{msec}$ are not accompanied by increases in reflex reduction when the ISI is $100 \mathrm{msec}$. The present data are consistent with these latter findings. The differences between them and the earlier findings by Ison may reflect differences in the ISI used and may also reflect the fact that gap onset was used by Ison as the reference point for determining the temporal distance between the gap and the onset of the SES, as discussed above.

In Experiment 1 it was noted that, of all the ISIs used, the 50-msec ISI tended to produce the greatest degree of reflex reduction, whereas the 25 -msec ISI tended to produce the least. It was also noted that the plot for the 25-msec ISI seemed to have the steepest slope, compared with the other plots. In Experiment 2, this trend was also found. For gaps $5 \mathrm{msec}$ in duration, an ISI of $50 \mathrm{msec}$ produced the greatest reduction in reflex amplitude, whereas the 20-msec ISI produced the least. As gap duration increased, there were no further increases in reflex reduction when an ISI of $50 \mathrm{msec}$ was used, as noted above. However, when the ISI was kept to $20 \mathrm{msec}$, increases in gap duration were accompanied by increases in reflex reduction until the gap duration reached $25 \mathrm{msec}$. At this point, mean startle amplitude was reliably smaller than it was for 25-msec gaps presented at a 50-msec ISI.

These findings are, for the most part, consistent with previous research. As previously mentioned, Ison (1982) demonstrated that gaps of increasingly longer duration continued to increase in their ability to reduce startle amplitude if they were presented at a brief ISI, while showing no pronounced tendency to do this if they were presented at longer ISIs. Although these trends exist in the present data, in contrast to Ison's research, increases in gap duration beyond $25 \mathrm{msec}$ become relatively ineffective in further reducing reflex amplitude even when presented at brief ISIs.

The data presented in Experiment 2 are consistent with the suggestion by Ison et al. (1991) that the ability of a very brief gap to reduce startle amplitude is dependent on a sufficient amount of time-dependent processing. Given a sufficient lead time, brief gaps are readily detectable; with ISIs of $50 \mathrm{msec}$ and longer, increases in gap duration beyond $5 \mathrm{msec}$ do not greatly increase the degree of reflex reduction obtained. If this processing time is decreased, as in the case of the briefest ISIs used in Experiment 2, brief gaps become harder to detect, as indicated by the startle amplitude reduction that they produce. At these short ISIs, gaps gradually increase in saliency until they reach a duration of about $25 \mathrm{msec}$. Apparently, the short ISI can be compensated for by the longer gap duration.

\section{EXPERIMENT 3}

The data collected in Experiment 1 indicated that gaps as brief as $1 \mathrm{msec}$ were reliably detected by the subjects. This value falls below the range of reported values that estimate the limit of auditory temporal resolution. It was suggested in Experiment 1 that this might reflect the use of a $1-\mathrm{msec}$ rise-fall time for the gaps, which may have enhanced the saliency of the gaps and made even very brief ones detectable. The present experiment investigated this by systematically varying gap duration and the risefall time of the gaps.

\section{Method}

Subjects. The subjects were 12 male albino Sprague-Dawley rats. They were similar in all respects to the subjects used in Experiments 1 and 2, and were housed under identical conditions.

Apparatus. The equipment used in Experiment 3 was identical to that used in Experiments 1 and 2. As in Experiments 1 and 2, the rise-fall time of each gap was controlled by increasing or decreasing the gain of a voltage-controlled amplifier; the controlling voltage was supplied by the output of a digital-to-analog converter, which was programmed to increase or decrease its output voltage according to a cosine function. Variations in the duration of the rise-fall time were produced by varying the number of steps used in increasing or decreasing the output of the digital-to-analog converter.

Procedure. The procedure used in Experiment 3 was very similar to that used in Experiment 1 . Within a given test session, gap duration was varied among $1,2,3,4,5,6,8$, and $10 \mathrm{msec}$. Also included were no-gap trials and zero-gap trials. These 10 types of trials were presented 30 times each in a block randomized sequence. Gaps were always presented at an ISI of $50 \mathrm{msec}$, since Experiments 1 and 2 indicated that this ISI produced maximal reflex reduction when used with brief gaps.

Each rat was exposed to six test sessions, spaced at least $48 \mathrm{~h}$ apart. Varied between test sessions for each rat was the rise-fall time of the gaps. The rise-fall times used were $.25, .5,1,1.5,2$, and $2.5 \mathrm{msec}$. These were presented to each rat in a sequence determined by a Latin square matrix. Thus, each subject was exposed to a total of 60 experimental conditions, representing the factorial combinations of the two independent variables.

\section{Results}

As in the first two experiments, mean startle amplitude was computed for each rat for each condition, and grand means were then computed across subjects for each condition. The grand means are depicted in Figure 3. Again, for the sake of clarity, the SEM is shown only for the gaps presented with a .25-msec rise-fall time; as in Experiments 1 and 2, the value of the SEM was about the same for all experimental conditions. The line parallel to the horizontal axis represents the mean, computed across the rise-fall times used, of the grand means for the no-gap condition.

It can be seen that varying the rise-fall time of a gap influenced its saliency. Gaps presented with a $.25-\mathrm{msec}$ rise-fall time routinely produced less reflex reduction than did those presented with any other. Furthermore, a 1-msec gap presented with a .25 -msec rise-fall time does not appear to be different from the no-gap and zero-gap control conditions. 


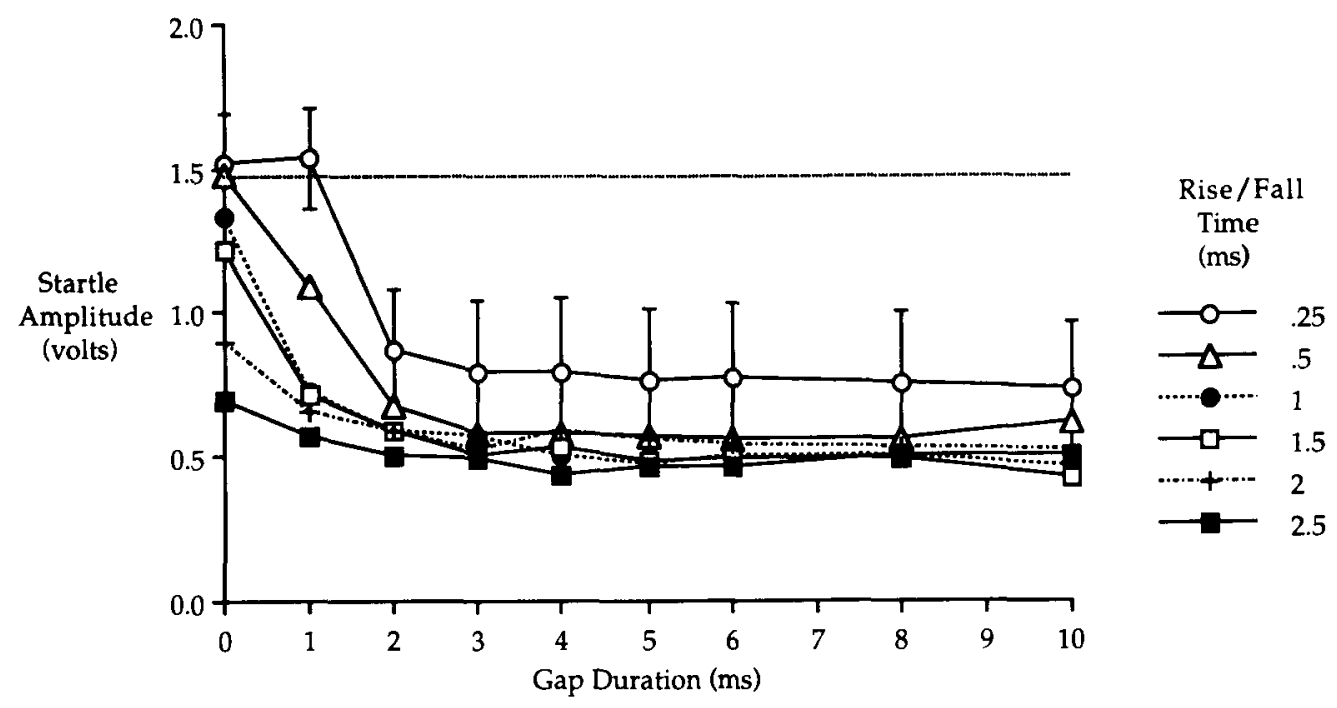

Figure 3. Mean startle amplitude as a function of gap duration and gap rise-fall time. The line at the top running parallel to the horizontal axis represents the grand mean of the "no gap" condition. (Vertical error bars for .25 -msec rise/fall time represent \pm 1 SEM.)

With the exception of the plot for the .25 -msec rise-fall time data, all of the functions in Figure 3 appear to be quite similar and describable with single straight lines except for the points representing the shortest gap durations. It can be seen that increasing the rise-fall time from .25 to $.5 \mathrm{msec}$ greatly enhances the ability of a $1-\mathrm{msec}$ gap to reduce startle amplitude. Increasing the rise-fall time to $1 \mathrm{msec}$ further increases the ability of a 1-msec gap to reduce startle amplitude, at which point a maximum is apparently reached; further increases in rise-fall time do not produce a greater degree of reflex reduction. It can also be seen for the zero-gap conditions that some of the rise-fall times used were by themselves capable of reflex amplitude reduction. The 1.5-, 2-, and $2.5-\mathrm{msec}$ rise-fall times apparently were able to reduce startle amplitude when compared with their no-gap counterparts.

These trends were tested for statistical reliability using a 10 (gap duration) $\times 6$ (rise-fall time) ANOVA with repeated measures on both factors. A main effect was found for gap duration $[F(9,649)=33.42, p<.001]$ and for rise-fall time $[F(5,649)=10.9, p<.001]$; their interaction was not reliable $[F(45,649)=.79$, n.s. $)$.

The data were further analyzed using post hoc Tukey tests. It was found that, overall, the $.25-\mathrm{msec}$ rise-fall time condition was reliably different from all others $(p<$ .05 ) and that the .5 -msec rise-fall condition was reliably different from the $2.5-\mathrm{msec}$ rise-fall condition. No other comparisons were reliably different.

It was also found that, overall, the no-gap and zerogap-duration conditions were reliably different from each other and from all others $(p<.05)$. Also, the 1 -msecgap-duration condition was reliably different from all others $(p<.05)$ except the 2-msec-gap-duration condition. No other comparisons were reliably different.
Although the interaction between gap duration and rise-fall time was not statistically reliable, assessing the relationship between these two variables was one of the a priori assumptions for Experiment 3. Accordingly, further analyses using post hoc Tukey tests were performed to investigate this issue. It was found that for a rise-fall time of $.25 \mathrm{msec}$, the no gap, zero gap, and 1-msec gap were not reliably different from each other but reliably different from all other durations, which in turn were not reliably different from each other. This indicated that the function for the .25 -msec rise-fall time leveled off at a gap duration of $2 \mathrm{msec}$. A similar pattern emerged for the .5-msec rise-fall time, except that the 1-msec-gapduration condition was reliably different from all others including the no-gap and zero-gap conditions $(p<.05)$.

The relationship among the various rise-fall times was also explored for the zero-gap and 1-msec gap-duration conditions using post hoc Tukey tests. It was found that for the zero-gap condition, rise-fall times of $.25, .5$, and $1 \mathrm{msec}$ were not reliably different from each other. They were reliably different from all others $(p<.05)$; the only exception was that the 1 - and 1.5 -msec rise-fall times were not reliably different from each other. The $1.5-\mathrm{msec}$ rise-fall time was reliably different from both the 2- and 2.5 -msec rise-fall times $(p<.05)$, which were not different from each other. For the 1-msec gap duration, the .25 - and the .5 -msec rise-fall times were reliably different from each other and from all others $(p<.05)$; no other comparisons were reliably different from each other.

\section{Discussion}

A number of conclusions can be inferred from these data. It appears that when presented with a brief rise-fall time, gaps of $2 \mathrm{msec}$ in duration are detectable. This is 
consistent with other studies that have estimated the limit of auditory temporal resolution. The present data also indicate that the subjects' ability to detect a 1-msec gap in Experiment 1 was probably due to the use of a $1-\mathrm{msec}$ rise-fall time. When presented with a rise-fall time of $.25 \mathrm{msec}$, a 1-msec gap was undetectable, whereas presenting it with a .5 -msec rise-fall time resulted in reliable reflex reduction. Although a $1-\mathrm{msec}$ rise-fall time presented alone (in the zero-gap condition) was not detectable, increasing it slightly to $1.5-\mathrm{msec}$ allowed reliable detection, in contrast to the no-gap condition. This makes sense, since a rise-fall time of $1 \mathrm{msec}$ would result in slightly less than $2 \mathrm{msec}$ of silence, whereas a rise-fall time of $1.5 \mathrm{msec}$ would result in slightly more than 2 msec of silence.

\section{GENERAL DISCUSSION}

A consistent finding in the present series of experiments is that very brief gaps can reliably reduce the amplitude of the rat's acoustic startle response. The present data indicate that for the rat, the shortest detectable gap had a duration of $2 \mathrm{msec}$ when presented with a very brief rise-fall time. The 2-msec figure found here is consistent with other estimates of the limit of temporal acuity in the mammalian auditory system (see, e.g., Forrest \& Green, 1987; Penner, 1975).

Indeed, it is remarkable that such brief pauses in ongoing noise can produce such profound alterations in the amplitude of a subsequently elicited reflex. In Experiment 3 , gaps only $2 \mathrm{msec}$ in duration were capable of reducing startle amplitude by approximately $65 \%$. This degree of reflex reduction is consistent with the findings of others working with pulses of noise or pure tones (see, e.g., Hoffman \& Ison, 1980) and is a further indication of the extreme sensitivity that reflex reduction offers as a tool for the assessment of sensory functioning. The present data also indicate that the ISI resulting in the most pronounced reflex reduction with the briefest detectable gaps is approximately $50 \mathrm{msec}$. This is consistent with previous research (Hoffman et al., 1980) and indicates that this is the ISI of choice if one wants to assess the limits of, or subtle changes in, auditory temporal resolution in rats.

It has been proposed that the limit of the auditory system's ability to resolve temporal detail is imposed by the extent to which the time course of neural activity outlasts the physical stimulus that initiated the activity (see, e.g., Penner, 1975; Plomp, 1964). The detectability of a gap would therefore be determined by the rate of decay of such neural activity. This activity would have to decay sufficiently after gap onset so that it would be discriminably different from the following increase in neural activity produced by the gap offset. If this is true, then, as indicated by the zero-gap condition in Experiment 3, a decay in activity sufficient for detection was permitted by a 1.5$\mathrm{sec}$ rise-fall time but not by a $1-\mathrm{msec}$ rise-fall time.

It also follows from this that the family of curves seen in Figure 3 may be interpreted as a behavioral represen- tation of the decay of neural activity in the auditory system for an ongoing stimulus terminated with varying degrees of abruptness. Thus, besides documenting the time needed for the decay to occur, the figure also allows the shape of the decay to be seen. For the stimulus terminated most abruptly, the $.25-\mathrm{msec}$ rise-fall condition, the decay of neural activity appears to be curvilinear and fast, taking only about 2 or $3 \mathrm{msec}$.

Ison (1982) proposed that two different processes are involved in the ability of brief gaps in ongoing noise to reduce the amplitude of the rat's acoustic startle reflex. One is seen when very brief gaps are presented at long ISIs, and it is relatively insensitive to increases in gap duration beyond approximately $5 \mathrm{msec}$. The other, evident at short ISIs, appears to be dependent on gap duration for expression and develops slowly and steadily over a much greater range of gap durations.

The present findings are consistent with this proposition. At ISIs of $50 \mathrm{msec}$ and longer, the ability of gaps to reduce startle amplitude behave in accordance with other sorts of prestimuli, as documented by Hoffman and Ison (1980). At the most effective ISI, $50 \mathrm{msec}$, reflex amplitude decreased as gap duration increased from 0 to 3 msec. At this gap duration, further increases in gap duration had no further effect on startle amplitude. Startle amplitude was reduced to about $40 \%$ of control values (i.e., reflex amplitude was reduced by $60 \%$ ) by gaps of $3 \mathrm{msec}$ in duration, and the bulk of research points to this figure as a ceiling beyond which further gains in reflex reduction are not obtainable. At greater, nonoptimum ISIs, reflex reduction is not maximal and further gains in reflex reduction toward the maximum can be obtained by increasing the duration of the stimulus.

At ISIs of less than $50 \mathrm{msec}$, another process might be at work. It is different because it increases gradually and in a roughly linear fashion over a much greater range of gap durations, becoming maximal at durations of approximately $30 \mathrm{msec}$. Startle amplitude was reduced here to about $15 \%$ of control values, which is a much greater degree of reflex reduction than has been previously reported. These differences are best illustrated by comparing the plot for the 20 -msec ISI with the plot for the 50 -msec ISI in Figure 2. The shapes of the two functions are quite different, suggesting that the underlying mechanism might be different.

To understand what these two processes might be, it is necessary to speculate about the neural structures that support the processing of gaps. A fair amount is known about the structures involved in both the acoustic startle response and startle amplitude reduction, and this information suggests possible neural substrates for gap detection. The neural circuit for the acoustic startle reflex itself has been demonstrated to involve the auditory nerve, the ventral cochlear nucleus, the nuclei of the lateral lemniscus, the nucleus reticularis pontis cauadalis of the hindbrain (where the motor components of the startle reflex are probably coordinated), spinal interneurons, and lower motor neurons before being elaborated by the various 
muscle groups involved (Davis, Gendelman, Tischler, \& Gendelman, 1982; Leitner, Powers, \& Hoffman, 1980). Thus, the reflex is almost completely supported by hindbrain structures.

Startle amplitude reduction appears to involve a pathway that parallels this, diverging at the level of the lateral lemniscus and ascending to the level of the inferior colliculus of the midbrain, then descending via the lateral tegmental area into the hindbrain. The inferior colliculus may be the site at which the processing of prestimuli initiate the neural activity that eventually reduces startle amplitude (Leitner \& Cohen, 1985; Leitner, Powers, Stitt, \& Hoffman, 1981; Saitoh, Tilson, Shaw, \& Dyer, 1987). Electrophysiological evidence suggests that at least part of the inhibitory interaction between the neural activity engendered by a prestimulus and that produced by a subsequent SES occurs at or before the nucleus reticularis pontis cauadalis (Wu, Suzuki, \& Siegel, 1988).

The acoustic prestimuli used in the neurophysiological research mentioned above were brief bursts of either white noise or pure tones. It is possible that gaps are processed in the same manner, and the limits imposed on gap detection identified in the present research would therefore be set by structures in the auditory system at the level of the hindbrain or the midbrain. The functional decortication work performed on rats by Ison et al. (1991) suggests that this may be too simple a conclusion, however. After bilateral topical application of a potassium chloride solution to the dura overlying the rats' cortex, Ison et al. found that brief (2-15 msec) gaps presented at a $100-\mathrm{msec}$ ISI no longer reduced acoustic startle amplitude. Startle amplitude reduction produced by prestimuli consisting of noise offset (i.e., the leading edge of a gap) at short (30 msec and less) ISIs and by pulses of noise was not affected by this manipulation.

Given this differential sensitivity of different ISIs to functional decortication, and the different time courses for amplitude reduction by gaps produced by different ISIs, Ison et al. (1991) proposed that brief gaps become detectable at long ISIs because of the greater time available for processing these mild stimuli and that this extra processing depended on a functional cortex. In the present research, this would be the process that was relatively insensitive to increases in gap duration beyond approximately $5 \mathrm{msec}$. The second process, which in the work conducted by Ison et al. and in the present study was much more dependent on gap duration for expression, does not involve a functional cortex. On the basis of the neurophysiological evidence discussed above, it is possible that the inferior colliculus is involved in this second process.

As noted by Ison et al. (1991), functional decortication by topical potassium chloride application alters activity in the cortex and also in other areas of the brain that require cortical input for normal functioning (see, e.g., Weiss, 1961). It is therefore possible that the effects of functional decortication on brief gaps presented at long ISIs are indicative of a disruption of function in such a noncortical area of the brain. Thus, such data do not re- quire that amplitude reduction produced by brief gaps presented at long ISIs be the result of processing in the cortex itself-they only require that there be some cortical influence in the area where the processing occurs. It is thus entirely possible that the inferior colliculus is also involved in the processing of brief gaps presented at long ISIs and that its influence on startle may be modulated by cortical input to the lateral tegmental area of the midbrain reticular formation. The activity of the midbrain reticular formation has been shown to change after functional decortication (Weiss, 1961).

If, as proposed by Ison et al. (1991), longer processing time is indeed the reason why amplitude reduction can be produced by very brief gaps that are presented at long ISIs, the explanation must be extended to account for why, in the present study, a 50-msec ISI appears to be ideal for the detection of brief gaps. As has been documented in this series of experiments, ISIs that are longer, as well as shorter, than $50 \mathrm{msec}$ are not as effective in reducing startle amplitude, yet it would seem that the longer ISIs would afford an even greater amount of time for the processing of the brief stimuli and thus further enhance its detectability. Perhaps at ISIs beyond $50 \mathrm{msec}$, the sensory "trace" of the gap begins to fade, and it therefore becomes a less salient stimulus.

\section{REFERENCES}

Benham-Dunster, R. A., \& Dunster, J. R. (1985). Hearing loss in the developmentally handicapped: A comparison of three audiometric procedures. Journal of Auditory Research, 25, 175-190.

Buus, S., \& Florentine, M. (1985). Gap detection in normal and impaired listeners: The effects of level. In A. Michelson (Ed.), Time resolution in auditory systems (pp. 159-179). Berlin: Springer-Verlag.

Corso, J. F., Corso, G. M., \& Corso, C. A. (1981, April). Prediction of speech discrimination from temporal discrimination measures. Paper presented at the meeting of the Eastern Psychological Association, New York

Crofton, K. M. (1992). Reflex modification and the assessment of sensory dysfunction. In H. Tilson \& C. Mitchell (Eds.), Neurotoxicology (pp. 181-211). New York: Raven Press.

Davis, M., Gendelman, D. S., Tischler, M. D., \& Gendelman, P. M. (1982). A primary acoustic startle circuit: Lesion and stimulation studies. Journal of Neuroscience, 2, 791-805.

Davis, S. M., \& McCroskey, R. L. (1980). Auditory fusion in children. Child Development, 51, 75-80.

Dooling, R. J., Zoloth, S. R., \& Baylis, J. R. (1978). Auditory sensitivity, equal loudness, temporal resolving power, and vocalizations in the house finch (Carpodacus mexicanus). Journal of Comparative \& Physiological Psychology, 92, 867-876.

Fitzgibbons, P. J. (1984). Tracking a temporal gap in band-limited noise: Frequency and level effects. Perception \& Psychophysics, 35, 446-450

Forrest, T. G., \& Green, D. M. (1987). Detection of partially filled gaps in noise and the temporal modulation transfer function. Journal of the Acoustical Society of America, 82, 1933-1943.

Giraudi, D., Salvi, R., Henderson, D., \& Hamernik, R. (1980). Gap detection by the chinchilla. Journal of the Acoustical Society of America, 68, 802-806.

GreEN, D. M. (1985). Temporal factors in psychoacoustics. In A. Michelson (Ed.), Time resolution in auditory systems (pp. 122-140). Berlin: Springer-Verlag.

HAGGARD, M. (1985). Temporal patterning in speech: The implications of temporal resolution and patterning. In A. Michelson (Ed.), Time resolution in auditory systems (pp. 215-247). Berlin: Springer-Verlag. 
Hoffman, H. S., \& Ison, J. R. (1980). Reflex modification in the domain of startle: $I$. Some empirical findings and their implications for how the nervous system processes sensory information. Psychological Review, 87, 175-189.

Hoffman, H. S., StitT, C. L. \& Leitner, D. S. (1980). The optimum interpulse interval for inhibition of acoustic startle in the rat. Journal of the Acoustical Society of America, 68, 1218-1220.

Ison, J. R. (1982). Temporal acuity in auditory function in the rat: Reflex inhibition by brief gaps in noise. Journal of Comparative \& Physiological Psychology, 96, 945-954.

Ison, J. R., \&ofFMAN, H. S. (1983). Reflex modification in the domain of startle: II. The anomalous history of a robust and ubiquitous phenomenon. Psychological Bulletin, 94, 3-17.

Ison, J. R., O'ConNor, K., Bowen, G. P., Bocirnea, A. (1991). Temporal resolution of gaps in noise by the rat is lost with functional decortication. Behavioral Neuroscience, 105, 33-40.

Ison, J. R., \& Pinckney, L. A. (1983). Reflex inhibition in humans: Sensitivity to brief silent periods in white noise. Perception \& Psychophysics, 34, 84-88.

LAUTER, J. L., \& HirSh, I. J. (1985). Speech as temporal pattern: A psychoacoustical profile. Speech Communication, 4, 41-54.

LEITNER, D. S., \& CoHEN, M. E. (1985). Role of the inferior colliculus in the inhibition of acoustic startle in the rat. Physiology \& Behavior, 34, 65-70.

Leitner, D. S., Powers, A. S., \& Hoffman, H. S. (1980). The neural substrate of the startle response. Physiology \& Behavior, 25, 291-297.

Leitner, D. S., Powers, A. S., Stitt, C. L., \& Hoffman, H. S. (1981). Midbrain reticular formation involvement in the inhibition of acoustic startle. Physiology \& Behavior, 26, 259-268.

MarSh, R. R., Hofrman, H. S., StitT, C. L., \& SchwarTz, G. (1975). Role of small changes in the acoustic environment in modifying the startle reflex. Journal of Experimental Psychology: Animal Behavior Processes, 1, 235-244.

MCCroskey, R. L., \& Kidder, H. C. (1980). Auditory fusion among learning disabled, reading disabled and normal children. Journal of Learning Disabilities, 13, 18-25.
Penner, M. J. (1975). Persistence and integration: Two consequences of a sliding integrator. Perception \& Psychophysics, 18, 114-120.

Perrott, D. R., \&illiams, K. N. (1971). Auditory temporal resolution: Gap detection as a function of interpulse frequency disparity. Psychonomic Science, 25, 73-74.

Plomp, R. (1964). Rate of decay of auditory sensation. Journal of the Acoustical Society of America, 36, 277-282.

ReITER, L. A., \& Ison, J. R. (1977). Inhibition of the human eyeblink: An examination of the Wendt-Yerkes method for threshold detection. Joumal of Experimental Psychology: Human Performance \& Perception, 3, 325-336.

Saitoh, K., Tilson, H. A., Shaw, S., Dyer, R. S. (1987). Possible role of the brainstem in the mediation of prepulse inhibition in the rat. Neuroscience Letters, 75, 216-222.

Schwartz, G. M., Hoffman, H. S., Stitt, C. L., Marsh, R. R. (1976). Modification of the rat's acoustic startle response by antecedent visual stimulation. Journal of Experimental Psychology: Animal Behavior Processes, 2, 28-37.

Trinder, E. (1979). Auditory fusion: A critical interval test with implications in differential diagnosis. British Journal of Audiology, 13, 143-147.

WEISS, T. (1961). The spontaneous EEG activity of the mesencephalic reticular formation during cortical spreading depression. Physiologia Bohemoslovencia, 10, 109-115.

Williams, K. N., Elfner, L. F., \& Howse, W. R. (1979). Auditory temporal resolution: Effects of sensation level. Journal of Auditory Research, 19, 265-269.

Wu, M.-F., Suzuki, S. S., \& Siegel, J. M. (1988). Anatomical distribution and response patterns of reticular neurons active in relation to acoustic startle. Brain Research, 457, 399-406.

(Manuscript received June 12, 1992; revision accepted for publication February 19, 1993.) 